\title{
An investigation in the quality of diet and adequacy of energy and macronutrient intake amongst male and female university students
}

\author{
H. Foster, I. Alaunyte and F. Amirabdollahian \\ School of Health Sciences, Liverpool Hope University, Liverpool, L16 9JD
}

Previous studies have indicated university students are often exposed to stress, lack of time and financial constraints, adversely influencing nutrient intake and status ${ }^{(1)}$. Excessive calorie intake, high dietary fat intake, alcohol and fast food consumption are commonly seen in this population, compromising an optimum nutritional status ${ }^{(2)}$. The purpose of this study was to investigate quality of diet and the adequacy of energy and macronutrient intake in university students by comparing their current nutrient intake to Dietary Reference Values (DRVs).

After obtaining ethical approval, participants (n 234) aged 18-24 from North West Universities were recruited in a cross-sectional study. Laboratory and anthropometric measures of nutritional status such as glucose and lipid profiles, weight, height, percentage body fat and BMI were assessed. Energy and macronutrient intake was measured using a validated 3-day diet diary and analysed using dietary assessment software Microdiet. The percentage contribution of nutrients to total energy was compared with the DRVs ${ }^{(3-5)}$. Statistical analysis including one-sample T-test, chi square test and independent samples T-test was conducted using SPSS 22 and statistical significance was set at $0 \cdot 05$.

The average daily macronutrients intake of participants was often higher in males in comparison with females; however when macronutrient intakes were expressed in relation with energy intake and in comparison to DRVs, females had a significantly higher intake of fat, Saturated Fatty Acids (SFA), Poly Unsaturated Fatty Acids (PUFA), Mono Unsaturated Fatty Acids (MUFA), free sugar and protein; while total carbohydrate intake was lower than the DRVs. For males, total fat intake was not statistically above DRVs, however consumption of SFA, PUFA, MUFA, free sugar and protein were all higher compared to DRVs; while, carbohydrate intake was also lower than the DRVs. When energy requirement was calculated according to the latest DRVs for energy for all individuals ${ }^{(5)}, 76.8 \%$ of females and $78.0 \%$ of males met their daily energy requirement and there was no variation in meeting the requirements $(\mathrm{P}>0.05)$.

\begin{tabular}{|c|c|c|c|c|c|c|c|}
\hline \multirow{2}{*}{$\begin{array}{l}\text { Percentage contribution of } \\
\text { nutrients to total energy intake }\end{array}$} & \multicolumn{4}{|l|}{ Males } & \multicolumn{3}{|c|}{ Females } \\
\hline & $\overline{\text { DRVs }}$ & Mean & SD & $\overline{\text { Number }}$ & Mean & $\mathrm{SD}$ & Number \\
\hline Fat & 33 & $32 \cdot 5$ & $7 \cdot 1$ & 104 & $34.5 *$ & $7 \cdot 4$ & 134 \\
\hline SFA & 10 & $10 \cdot 8^{*}$ & $3 \cdot 3$ & 140 & $12 \cdot 2 *$ & $3 \cdot 8$ & 134 \\
\hline PUFA & $6 \cdot 5$ & $5 \cdot 1 *$ & $2 \cdot 1$ & 104 & $5 \cdot 5^{*}$ & $2 \cdot 6$ & 134 \\
\hline MUFA & 12 & $10 \cdot 6^{*}$ & $3 \cdot 3$ & 104 & $10 \cdot 7 *$ & $3 \cdot 4$ & 134 \\
\hline Carbohydrate & 50 & $43 \cdot 0^{*}$ & $9 \cdot 6$ & 104 & $45 \cdot 8^{*}$ & $8 \cdot 5$ & 134 \\
\hline Free sugar & 10 & $15 \cdot 4^{*}$ & $8 \cdot 2$ & 104 & $18 \cdot 0^{*}$ & $7 \cdot 0$ & 134 \\
\hline Protein & 15 & $21.7 *$ & 8.9 & 104 & $17.9 *$ & $6 \cdot 1$ & 134 \\
\hline $\begin{array}{l}\text { Percentage of daily intake in co } \\
\text { individuals daily energy requiren }\end{array}$ & & $78 \cdot 0$ & $28 \cdot 7$ & 102 & $76 \cdot 8$ & $25 \cdot 5$ & 131 \\
\hline
\end{tabular}

Percentage contribution of nutrients to total energy intake and percentage of daily energy intake in comparison with the nutrients and energy DRVs. $* \mathrm{P}<0 \cdot 05$ in one sample t-test

Although higher contribution of protein to total energy intake of male participants can explain part of the gender differences, the excessive intake of free sugar, total fat and SFA especially amongst females warrants further investigation. In contrast to previous studies demonstrating females often consume a better quality of diet ${ }^{(1)}$, this study has highlighted that this is not always the case.

1. Deliens T. Clarys P. Bourdeaudhui I.D et al. (2014) BMC Public Health 14, 1471-2458.

2. Alibabića V. Mujic I. Rudic D et al. (2014) Procedia - Social and Behavioural Sciences 116, 2137-40.

3. The Committee on the Medical Aspects of Food Policy (1991) Dietary Reference Values for Food Energy and Nutrients for the United Kingdom.

4. Scientific Advisory Committee on Nutrition, Dietary Recommendations for Carbohydrates: 2014

5. Scientific Advisory Committee on Nutrition, Dietary Recommendations for Energy: 2011 